\title{
Small-signal analysis and control implementation of boost converter fed PMDC motor for electric vehicle applications
}

\author{
Bader N. Alajmi*, Nabil A. Ahmed and A. K. Al-Othman \\ Electrical Engineering Department, College of Technological Studies, Public Authority for Applied Education and Training, Kuwait \\ *Corresponding Author: bn.alajmi@paaet.edu.kw
}

$\begin{array}{ll}\text { Submitted: } & 10 / 04 / 2020 \\ \text { Revised: } & 11 / 02 / 2021 \\ \text { Accepted: } & 21 / 02 / 2021\end{array}$

\begin{abstract}
Small-signal analysis of boost converter fed permanent magnet DC (PMDC) motor for electric vehicle applications is performed, and hardware implementation is realized in this paper. Extensive analysis is performed to identify the relevant steady-state and dynamic features of the proposed system with small-signal linearization, and relevant transfer functions are formulated. The nonlinear equations of the system are derived and then linearized around a stable operating point to construct a small-signal model. Transfer functions relating the control of the converter to the motor speed and control to input current are derived symbolically using computerized symbolic algebra in MathCAD. The control-to-output transfer functions are obtained by introducing perturbation in state variables, equating $\mathrm{AC}$ and DC quantities and proceeding with AC quantities. The principle of operation, operation modes, small-signal analysis, experimental verification, and the effectiveness of the speed control are discussed and presented. An experimental prototype is implemented using dSPACE DS1103-based digital signal processor, and the proposed model is used for online parameter tuning of the speed controller. The speed control dynamics and transient response are investigated under sudden load changes. The overall system performance is evaluated and verified experimentally based on a speed feedback control scheme for validation purposes.
\end{abstract}

Keywords: Small-signal model; Boost converter; PMDC motor; Closed-loop; Transfer function; dSPACE.

\section{INTRODUCTION}

DC motors can deliver high torque at starting and at low speeds and it is also likely to acquire speed control over a wide range. The methods of speed control are normally simpler and most economical than those of AC motors (Rashid, 2014; Bhatt et al., 2019). Both series and separately excited DC motors are normally utilized in variable-speed drives, traction, and electric vehicle applications (Jape \& Thosar, 2017; Alothman et al., 2016). Speed control of electric motors plays an important role in many industrial and domestic applications. AC motors exhibit highly coupled nonlinear and multivariable structure. The control of AC motors generally requires complex digital control techniques along with high switching power converters (Luthra, 2017). Their power converters are relatively complex, more expensive and require advanced feedback control techniques. Although the upcoming trend is toward AC motors, DC motors are presently used in many applications. It might be a few decades before the DC motors are completely replaced by AC motors. Permanent magnet DC (PMDC) motors have variable characteristics and are used extensively in adjustable speed applications and can provide a high starting torque and speed control over a wide range (Liu et al., 2016; Huynh \& Hsieh, 2018; Porselvi et al., 2018). The methods of speed control are normally simpler and less expensive than those 
of AC motors. Therefore, PMDC motors still play a significant role in modern industrial applications. The operation of the PMDC motor in different modes is extremely easy compared to AC motors. However, due to commutators PMDC motors are not suitable for extremely high-speed applications and require more maintenance than AC motors. The recent advancements in power electronics, control techniques, microcomputers and digital signal processors (DSP) made a revolution in modern industrial control equipment and adjustable-speed applications.

Generally, DC-DC converters have been commonly used in speed control applications of DC motors. This is mainly due to its rapid dynamic response, energy-efficient, flexibility and ease of control particularly at low speeds and low ripples in the armature current (AbdElhafez et al., 2017). In Guerrero et al. (2017), a buck-boost converter using MOSFET as a switch fed DC series motor is presented and concluded that this system possesses a good operation performance with a minimum ripple in the output of the motor current and voltage. In Lachkar et al. (2006), the authors have considered a back-stepping design technique in the controller design to control DC motors through AC-DC power converters of the buck-boost type, to achieve speed regulation and unity power factor. Hridya et al. (2018) have introduced a circuit design to control DC motors using a Buck-Boost converter that has an advantage of smaller circuit along with less switching and copper losses. The dynamic model and steady state equivalent circuit of a single-phase AC-DC buck-boost converter fed DC motor with uniform PWM control is presented in Ahmed (2005).

The performance of neural network controller and that of traditional controllers for Buck-Boost converter fed DC motor are compared in Stephen \& Devaprakash (2014), where it was found that ANN controller based on pulse area modulation performs better in terms of dynamic control when compared to other controllers due to its heuristics nature. Other techniques based on heuristic search algorithms were also proposed. Ragavendra et al. (2014) and Tarannum (2019) proposed the application of artificial bee colony algorithm in the control of Cuk converter fed DC motor to control the speed. Authors claim that this method has the advantage of improving both the efficiency and power factor. Fuzzy logic control (FLC) has been used to control the speed of the DC motor based on LabVIEW program. The FLC controller is designed to apply the required control voltage sent to DC motor based on fuzzy rule base of motor speed error (Ohri \& Naveen, 2013), and it is concluded that the FLC is sensitive to the variation of the reference speed.

Develop tools for modeling, analysis, and design of DC-DC converter are the key to design the control of overall system and are crucial to study system stability and dynamic performance. Dynamic models of converters are needed to study: (1) how do AC variations in input voltage $v_{\text {in }}(t)$ or the duty cycle $d(t)$ affect the motor speed? (2) What are the small-signal transfer functions of the converter? (3) Extend the steady-state converter models to include continuous current mode (CCM) and discontinuous current mode (DCM) dynamics. (4) Construct converter small-signal transfer functions. (5) Design converter control systems. (6) Programming control of converters. Small-signal modeling is an attractive tool in investigating the stability and dynamic performance of a given system (Arjun et al., 2019; Barry et al., 2018; Barry et al., 2016). It enables the determination of control-to-output transfer function, which describes how variations or disturbances in the input of a given system lead to disturbances in the output performance (Kondrath \& Kazimierczuk, 2012; Shin \& Kazimierczuk, 2003; Qiu et al., 2014). A small-signal analysis-based approach has been adopted in Dash et al. (2014), where a dynamic model of a Z-source converter fed DC motor loaded with a pump is presented. Small-signal model analysis of different power converters only has been reported in the literature (Zhang \& Guo., 2019; Love, 2007; Viswanatha, 2019). However, an analysis combining both boost converter and DC motors has not been considered yet.

In this paper, a small-signal model of the speed control operation of a boost converter fed PMDC motor is developed for the first time. Extensive analysis is performed to identify the relevant steady-state and dynamic features of the proposed system with small-signal linearization and relevant transfer functions are formulated. A transfer function relating to the control of the converter, i.e. duty cycle, to the output speed of the DC motor and control-to-input current transfer functions are derived symbolically in Mathcad software (MATHCAD, 2019). The derivations have been obtained by computational symbolic algebra, avoiding the requirement for simplifying assumptions. The proposed model is used for online parameter tuning of the speed controller and it is verified by simulation and experimental results, with the control scheme being carried out using dSPACE DS1103 control board. Thereby, the control implementation and acquisition of motor speed are executed in real-time. 


\section{CIRCUITS DESCRIPTIONS AND PRINCIPLE OF OPERATION}

The schematic diagram and system configuration of boost DC-DC converter fed PMDC motor are shown in Fig. 1. The principle of operation can be explained by Fig. 1. When the chopper switch is switched on, the converter diode is reversing bias, and the output stage is isolated from the input. The input source supplies energy to the boost inductor, the boost inductor current increases linearly, and energy is stored in the inductor. When the chopper switch is switched off, the energy stored in the boost inductor is transferred to the motor through the diode and the boost inductor current decreases linearly. The output stage receives energy from the input source and the boost inductor. Therefore, the output voltage is boosted. The output voltage is maintained constant by connecting a large capacitor across the motor terminal and it will be continuous, and its value will be the average value. The voltage across the motor by varying the duty cycle $\mathrm{D}$, and the minimum motor voltage is the supply voltage $V_{s}$ when the duty cycle equals zero.

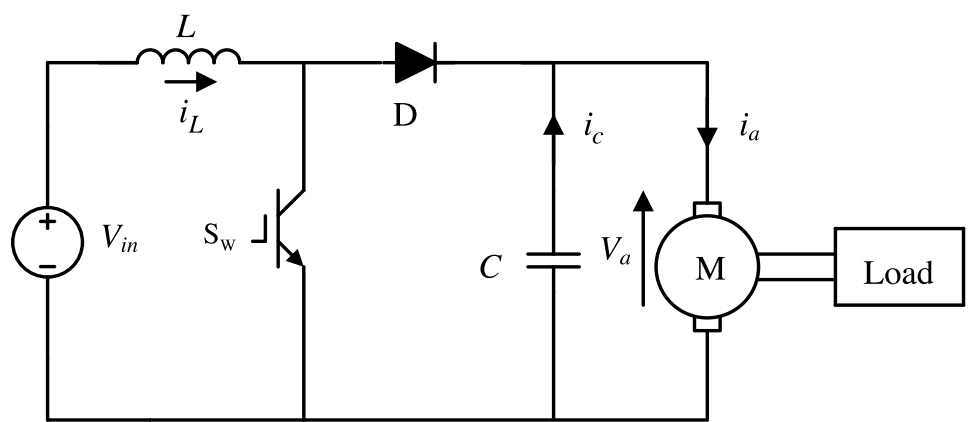

Fig. 1. System configuration of Boost converter fed PMDC motor.

\section{OPERATION MODES}

The operation principle during one switching period is divided into two switching modes: charging and discharging modes. The equivalent circuit during each mode is depicted in Fig. 2, while Fig. 3 illustrates the steady-state voltage and current waveforms during one switching period.

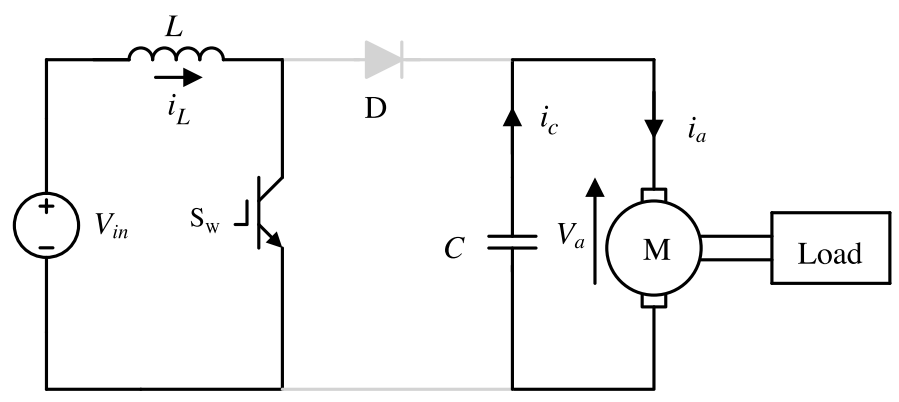

(a) Charging mode.

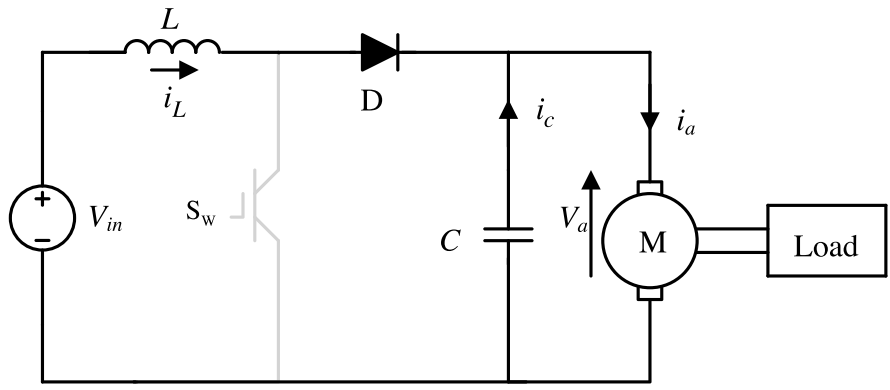

(b) Discharging mode.

Fig. 2. Equivalent circuits during operation modes. 


\section{A) Charging mode (Mode1)}

This mode is valid for the time $0 \leq t<D T_{s}$, the switch $S_{w}$ is closed and the diode $\mathrm{D}$ becomes reverse biased so the supply voltage $V_{s}$ appears across the inductor. The energy is transferred from the source $V_{s}$ to the inductor. The current $i_{L}$ increases linearly through the input side, as shown in Fig 2(a) resulting in charging the inductor. During this mode, the capacitor $\mathrm{C}$ and the motor terminals are disconnected from the supply. Therefore, the capacitor begins to discharge through the armature winding and the motor current continuous to flow through the capacitor $\mathrm{C}$. The system stays in this mode until the boost switch is turned off. The equivalent circuit of this mode is shown in Fig. 2(a) and the bold lines show the possible current paths during this charging mode.
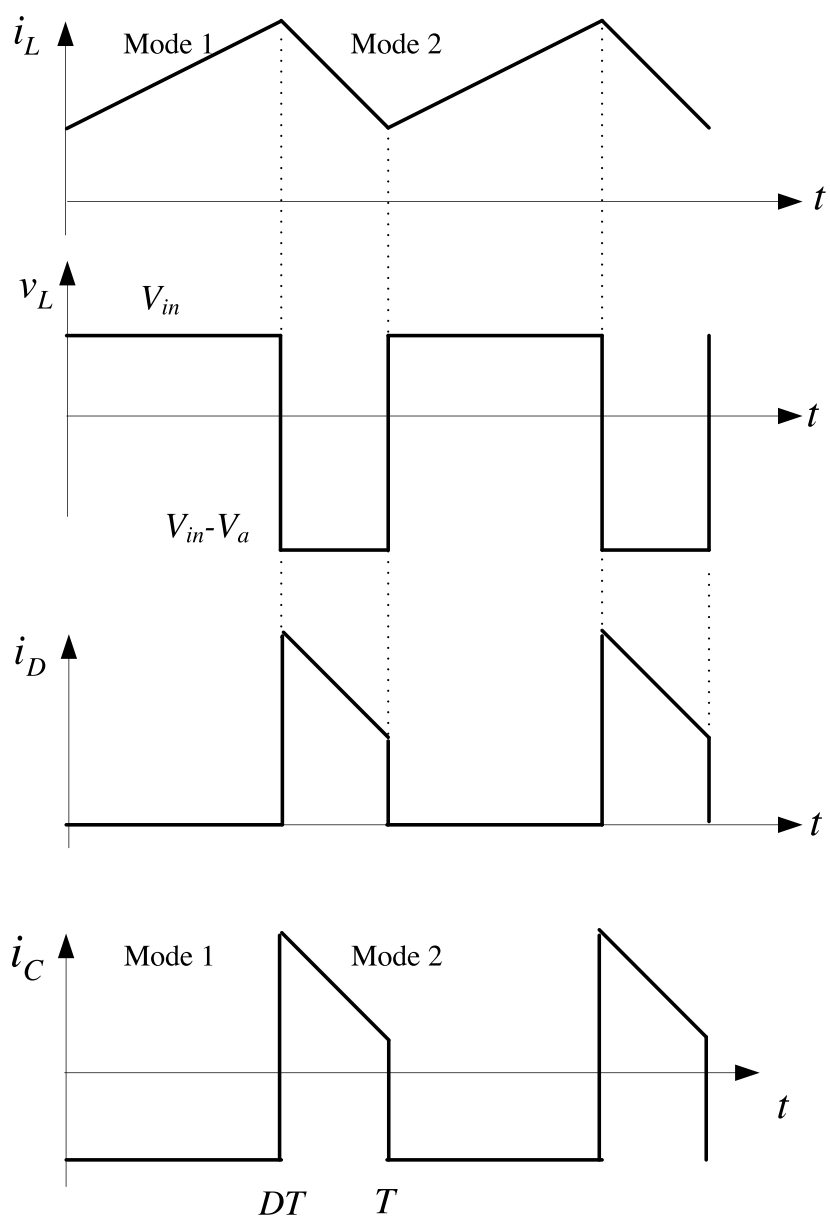

Fig. 3. Current and voltage waveform during one switching period.

The boost inductor current for mode 1 can be found from

$L \frac{d i_{L}}{d t}=V_{a}$

The motor current for mode 1 can be found from

$C \frac{d V_{a}}{d t}=-i_{a}$ 


\section{B) Discharging mode (Mode 2)}

During the off time $D T_{s}<t<T_{s}$ of the boost switch $S_{w}$, the converter diode will be forward biased and the inductor current decreases through the input and output sides. The output stage receives energy from the input source as well as from the boost inductor. Hence output becomes greater than the input voltage. Fig. 2(b) shows the equivalent circuit during this discharging mode. The boost inductor current for mode 2 can be found from

$$
\begin{aligned}
& L \frac{d i_{L}}{d t}=V_{i n}-V_{a} \\
& C \frac{d V_{a}}{d t}=i_{L}-i_{a}
\end{aligned}
$$

The armature voltage equation of a PMDC motor is given by

$$
\begin{aligned}
& V_{a}=E_{m}+R_{a} i_{a}+L_{a} \frac{d i_{a}}{d t} \\
& E_{m}=K_{e} \cdot w
\end{aligned}
$$

and the electromagnetic torque equation can be written as

$$
T_{m}=K_{T} \cdot i_{a}
$$

Averaging over one switching period (Abbasi et al., 2019; Ayachit \& Kazimierczuk, 2019), the averaged state equations are averaged over a switching cycle can be derived as

$$
\begin{aligned}
& L \frac{d i_{L}}{d t}=V_{i n}-(1-d) V_{a} \\
& C \frac{d V_{a}}{d t}=(1-d) i_{L}-i_{a}
\end{aligned}
$$

Then substituting for the armature current:

$$
\begin{aligned}
& L \frac{d i_{L}}{d t}=V_{i n}-(1-d) \cdot\left(K_{e} \cdot w+R_{a} i_{a}+L_{a} \frac{d i_{a}}{d t}\right) \\
& C \frac{d}{d t}\left(K_{e} \cdot w+R_{a} i_{a}+L_{a} \frac{d i_{a}}{d t}\right)=(1-d) i_{L}-i_{a}
\end{aligned}
$$

The fundamental torque equation for the PMDC motor-load (constant field):

$$
J \frac{d w}{d t}+B . w=K_{T} \cdot i_{a}-T_{L}
$$

Introducing perturbation around the steady-state values of the state variables and input voltage in eqs. $(10,11$, and 12$)$ such that $d=D+\hat{d}, w=\omega+\hat{\omega}, V_{i n}=v_{i n}-\hat{V}_{i n}, i_{L}=I_{L}+\hat{i}_{L}, i_{a}=I_{a}+\hat{i}_{a}$ (Khatun et al., 2020; Forouzesh et al., 2016). 


$$
\begin{aligned}
& L \frac{d}{d t}\left(I_{L}+\hat{i}_{L}\right)=\left(v_{i n}-\hat{V}_{i n}\right)-(1-D-\hat{d}) \cdot\left(K_{e} \cdot(\omega+\hat{\omega})+R_{a}\left(I_{a}+\hat{i}_{a}\right)+L_{a} \frac{d}{d t}\left(I_{a}+\hat{i}_{a}\right)\right) \\
& C \frac{d}{d t}\left(K_{e} \cdot(\omega+\hat{\omega})+R_{a}\left(I_{a}+\hat{i}_{a}\right)+L_{a} \frac{d}{d t}\left(I_{a}+\hat{i}_{a}\right)\right)=(1-D-\hat{d}) \cdot\left(I_{L}+\hat{i}_{L}\right)-\left(I_{a}+\hat{i}_{a}\right) \\
& J \frac{d}{d t}(\omega+\hat{\omega})+B \cdot(\omega+\hat{\omega})=K_{T} \cdot\left(I_{a}+\hat{i}_{a}\right)
\end{aligned}
$$

Equating AC and DC quantities and neglecting higher order perturbation terms (Kapat et al., 2020; Zhang et al., 2020), the small-signal model of the system can be written as follows:

$$
\begin{aligned}
& L \frac{d \hat{i}_{L}}{d t}=\hat{V}_{i n}-(1-D) \cdot K_{e} \cdot \hat{\omega}-(1-D) \cdot R_{a} \cdot \hat{i_{a}}-(1-D) \cdot L_{a} \cdot \frac{d \hat{i}_{a}}{d t}+\hat{d} \cdot K_{e} \cdot \omega+\hat{d} \cdot R_{a} \cdot I_{a} \\
& C \cdot K_{e} \frac{d \hat{\omega}}{d t}+C \cdot R_{a} \frac{d \hat{\imath}_{a}}{d t}+C \cdot L_{a} \frac{d^{2} \hat{\imath}_{a}}{d t^{2}}=-\hat{d} \cdot I_{L}+(1-D) \hat{\imath}_{L}-\hat{\imath}_{a} \\
& J \frac{d \hat{\omega}}{d t}+B \cdot \hat{\omega}=K_{T} \cdot \hat{i}_{a}
\end{aligned}
$$

By taking the Laplace transform of both side of the system equation (Grasso F., Manetti S., Maria C. P. and Reatti, 2018), the following equation in Laplace domain are formed:

$$
\begin{aligned}
& \text { s. L. } \hat{\imath}_{L}(s)+(1-D) \cdot\left(L_{a} \cdot s+R_{a}\right) \cdot \hat{\imath}_{a}(s)+k_{e}(1-D) \cdot \widehat{\omega}(s)=\hat{V}_{i n}(s)+\hat{d}(s) \cdot k_{e} \cdot \omega+\hat{d}(s) \cdot R_{a} I_{a} \\
& k_{e} C \cdot s \cdot \hat{\omega}(s)+\left[R_{a} C \cdot s+L_{a} C \cdot s^{2}+1\right] \cdot \hat{i}_{a}(s)-(1-D) \cdot \hat{i}_{L}(s)=\hat{d}(s) \cdot I_{L} \\
& (J . s+B) \cdot \hat{\omega}(s)-K_{T} \cdot \hat{i}_{a}(s)=0
\end{aligned}
$$

In matrix form, the system equations can be rearranged as

$$
\left[\begin{array}{ccc}
s . L & (1-D)\left(R_{a}+S . L_{a}\right) & K_{e}(1-D) \\
(D-1) & \left(C . L_{a} \cdot s^{2}+R_{a} C . s+1\right) & C K_{e} \cdot S \\
0 & -K_{T} & \text { J.s }+B
\end{array}\right]\left[\begin{array}{c}
\hat{\imath}_{L}(s) \\
\hat{l}_{a}(s) \\
\widehat{\omega}(s)
\end{array}\right]=\left[\begin{array}{c}
k_{e} \omega+I_{a} R_{a} \\
-I_{L} \\
0
\end{array}\right] \cdot \hat{d}(s)+\left[\begin{array}{l}
1 \\
0 \\
0
\end{array}\right] \cdot \hat{V}_{i n}(s)
$$

Therefore, the boost converter and the DC motor transfer functions can be obtained by solving matrix:

$$
\left[\begin{array}{l}
\hat{\imath}_{L}(s) \\
\hat{\imath}_{a}(s) \\
\widehat{\omega}(s)
\end{array}\right]=\left[\begin{array}{ccc}
s . L & (1-D)\left(R_{a}+S \cdot L_{a}\right) & K_{e}(1-D) \\
(D-1) & \left(C . L_{a} \cdot s^{2}+R_{a} C \cdot s+1\right) & C K_{e} \cdot S \\
0 & -K_{T} & J . s+B
\end{array}\right]^{-1}\left[\begin{array}{c}
k_{e} \omega+I_{a} R_{a} \\
-I_{L} \\
0
\end{array}\right] \cdot \hat{d}(s)+\left[\begin{array}{l}
1 \\
0 \\
0
\end{array}\right] \cdot \hat{V}_{i n}(s)
$$


Let's define the following matrices as

$$
A=\left[\begin{array}{ccc}
s . L & (1-D)\left(R_{a}+S . L_{a}\right) & K_{e}(1-D) \\
(D-1) & \left(C . L_{a} . s^{2}+R_{a} C . s+1\right) & C K_{e} . S \\
0 & -K_{T} & J . s+B
\end{array}\right] \text { and } X=\left[\begin{array}{c}
\hat{i}_{L}(s) \\
\hat{i}_{a}(s) \\
\hat{\omega}(s)
\end{array}\right]
$$

Using computerized symbolic algebra, the inverse matrix $A$ is computed without any assumptions:

$$
\begin{aligned}
& A^{-1}=\frac{1}{|A|} \cdot\left[\begin{array}{ccc}
\left(C J L_{a}\right) s^{3}+\left(B C L_{a}+C J R_{a}\right) s^{2}+\left(J+B C R_{a}+C K_{T} K_{e}\right) s+B & -(1-D)\left[J L_{a} s^{2}+\left(J R_{a}+B L_{a}\right) s+\left(B R_{a}+K_{T} k_{e}\right)\right] & \ldots \\
(1-D)(J \cdot s+B) & J L . s^{2}+B L . s & \ldots \\
(1-D) K_{T} & L K_{T} s & \ldots
\end{array}\right. \\
& \left.\begin{array}{cc}
\cdots & -K_{e}(1-D) \\
\cdots & -C L K_{e} s^{2}+(D-1)^{2} k_{e} \\
\cdots & C L_{a} L . s^{3}+C . L . R_{a} s^{2}+(1-D)^{2} L_{a} L . s+(1-D)^{2} R_{a}
\end{array}\right]_{3 \times 3}
\end{aligned}
$$

where $|A|$ is the determinant of matrix $A$ :

$$
\begin{gathered}
|A|=\left(J \cdot C \cdot L_{a} L\right) s^{4}+\left(J \cdot C \cdot L \cdot R_{a}+B \cdot C \cdot L_{a} L\right) s^{3}+\left(J \cdot L+B \cdot C \cdot L \cdot R_{a}+K_{T} \cdot K_{e} \cdot L \cdot C+J \cdot L_{a}(D-1)^{2}\right) s^{2}+\ldots \\
\left(L \cdot B+(D-1)^{2} \cdot L_{a} \cdot B+(D-1)^{2} \cdot R_{a} \cdot J\right) s+\left(K_{T} \cdot K_{e}+R_{a} \cdot B\right)(D-1)^{2}
\end{gathered}
$$

Solving eq. (23) to obtain $X$,

$$
\begin{aligned}
& {\left[\begin{array}{l}
\hat{i}_{L}(s) \\
\hat{i}_{a}(s) \\
\hat{\omega}(s)
\end{array}\right]=\frac{1}{|A|} \cdot\left[\begin{array}{cc}
\left(C J L_{a}\right) s^{3}+\left(B C L_{a}+C J R_{a}\right) s^{2}+\left(J+B C R_{a}+C K_{T} K_{e}\right) s+B & -(1-D)\left[J L_{a} \cdot s^{2}+\left(J R_{a}+B L_{a}\right) s+\left(B R_{a}+K_{T} k_{e}\right)\right] \\
(1-D)(J \cdot s+B) & J L . s^{2}+B L . s \\
(1-D) K_{T} & L K_{T} \cdot s
\end{array}\right.} \\
& \left.\begin{array}{lc}
\cdots & -K_{e}(1-D) \\
\cdots & -C L K_{e} s^{2}+(D-1)^{2} k_{e} \\
\cdots & C L_{a} L . s^{3}+C . L . R_{a} \cdot s^{2}+(1-D)^{2} L_{a} L \cdot s+(1-D)^{2} R_{a}
\end{array}\right] \cdot\left[\begin{array}{c}
k_{e} \omega+I_{a} R_{a} \\
-I_{L} \\
0
\end{array}\right] . \hat{d}(s)+\left[\begin{array}{l}
1 \\
0 \\
0
\end{array}\right] \cdot \hat{V}_{i n}(s)
\end{aligned}
$$

The control-to-output speed transfer function:

$$
\frac{\widehat{\omega}(s)}{\widehat{d}(s)}=\frac{1}{|A|}\left[\left(-L \cdot K_{T} \cdot I_{L}\right) s+(1-D) k_{T} \cdot\left(\omega \cdot K_{e}+R_{a} \cdot I_{a}\right)\right]
$$

The control-to-input current transfer function:

$$
\begin{aligned}
& \frac{\hat{\iota}_{L}(s)}{\hat{d}(s)}=\frac{1}{|A|}\left[C L_{a} J\left(\omega K_{e}+R_{a} I_{a}\right) s^{3}+\left(B C L_{a}+C J R_{a}\right) \cdot\left(\omega \cdot K_{e}+R_{a} \cdot I_{a}\right)+J \cdot L_{a} I_{L}(1-D) \cdot s^{2}+(1-D) \ldots\right. \\
& \left.\left[\left(J R_{a}+B L_{a}\right) I_{L}+\left(J+B R_{a} C+K_{T} K_{e} C\right) \cdot\left(\omega \cdot K_{e}+R_{a} \cdot I_{a}\right)\right] \cdot s+B\left(\omega K_{e}+R_{a} I_{a}\right)-\left(R_{a} B+K_{e} k_{T}\right) I_{L}\right]
\end{aligned}
$$


Table 1. Simulation constants and motor parameters.

\begin{tabular}{|c|c|c|c|}
\hline \multicolumn{2}{|r|}{ Parameter } & Symbol & Value \\
\hline \multirow{7}{*}{$\begin{array}{c}\text { Motor } \\
\text { parameters }\end{array}$} & Motor rated voltage & $V_{\text {in }}$ & $200[V]$ \\
\hline & Motor rated power & $P$ & $1.0[k W]$ \\
\hline & Armature resistance & $R_{a}$ & $0.78[\Omega]$ \\
\hline & Armature inductor & $L_{a}$ & $16[m H]$ \\
\hline & Motor constant & $K_{m}$ & $1.299[\mathrm{~V} /(\mathrm{rad} / \mathrm{s})]$ \\
\hline & Moment of inertia & $J$ & $0.05\left[\mathrm{~kg} \cdot \mathrm{m}^{2}\right]$ \\
\hline & Viscous friction constant & $B$ & $0.01[\mathrm{~N} . \mathrm{m} / \mathrm{rad} / \mathrm{s}]$ \\
\hline \multirow{6}{*}{$\begin{array}{c}\text { Boost } \\
\text { converter }\end{array}$} & DC supply voltage & $V_{s}$ & $30.0[V]$ \\
\hline & Boost inductor & $L$ & $33.0[\mathrm{mH}]$ \\
\hline & Capacitor & $C$ & $330[\mu F]$ \\
\hline & POWEREX CM150DY-12H IGBT & $S_{w}$ & \\
\hline & CS241210 fast recovery diode & $D$ & \\
\hline & Switching frequency & $f_{s}$ & $5.0[\mathrm{kHz}]$ \\
\hline \multirow{2}{*}{ PI Controller } & Proportional gain & $K_{p}$ & 0.001304 \\
\hline & Integral gain & $K_{i}$ & 0.00486 \\
\hline
\end{tabular}

The effectiveness of the proposed analysis and the transient behavior of boost converter fed DC motor is demonstrated and the overall system is simulated in the Matlab/Simulink (Matlab, 2019b). The simulation constants and motor parameters used for simulation are presented in Table 1. Substituting these parameters in eq. (27), controlto-output transfer function can be given as

$$
\frac{\widehat{\omega}(s)}{\widehat{d}(s)}=\frac{-5.442 e 06 s+4.474 e 09}{s^{4}+48.96 s^{3}+2.062 e 05 s^{2}+7.571 e 05 s+3.114 e 07}
$$

Figs. 4 and 5 illustrate the system bode plot as an important measure of system stability at different boost inductor values and different loads. It is obvious that the bode plot of the system gain is smooth and the system operates in stable operation at frequencies less than $10 \mathrm{rad} / \mathrm{s}$. The gain is $0 \mathrm{~dB}$, which means that the motor's speed will be similar to the reference speed and the system with this controller can follow efficiently the reference command. In the same frequency range, the phase is close to 0 degrees, which means that the output will not lag the input. The values of $0 \mathrm{~dB}$ at 0 degrees implies a perfect agreement between the tracking performance of the controller and the plant. Also, the gain plot shows that the system response overshoots the speed command and comes back to it. Despite the peaking in the gain response, the phase does not oscillate about the reference in the frequency response. 

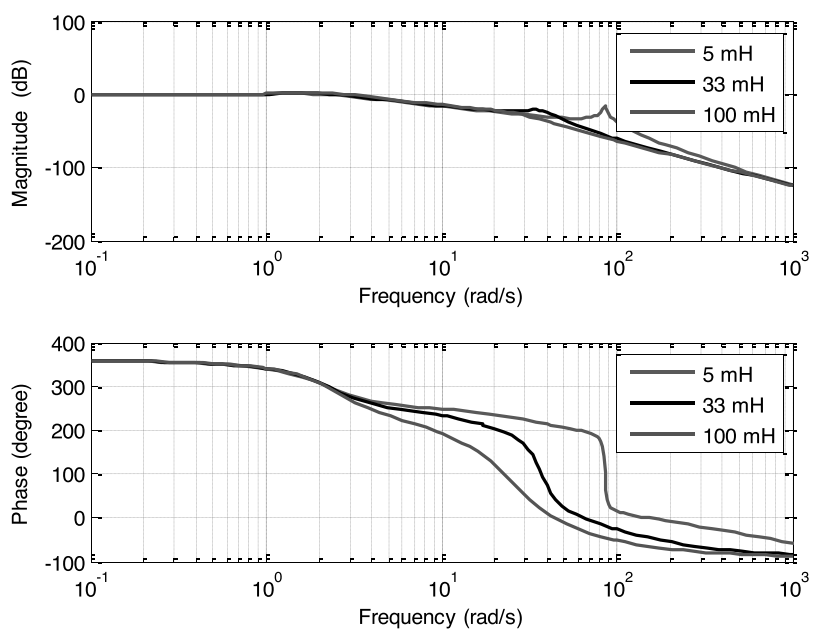

Fig. 4. System bode plot diagram at different boost inductor values.
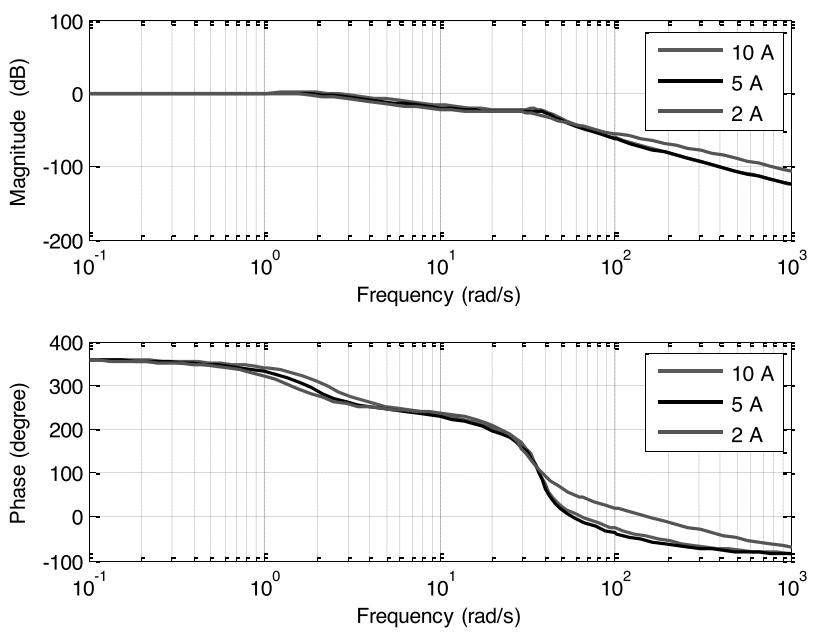

Fig. 5. System bode plot diagram at different armature current.

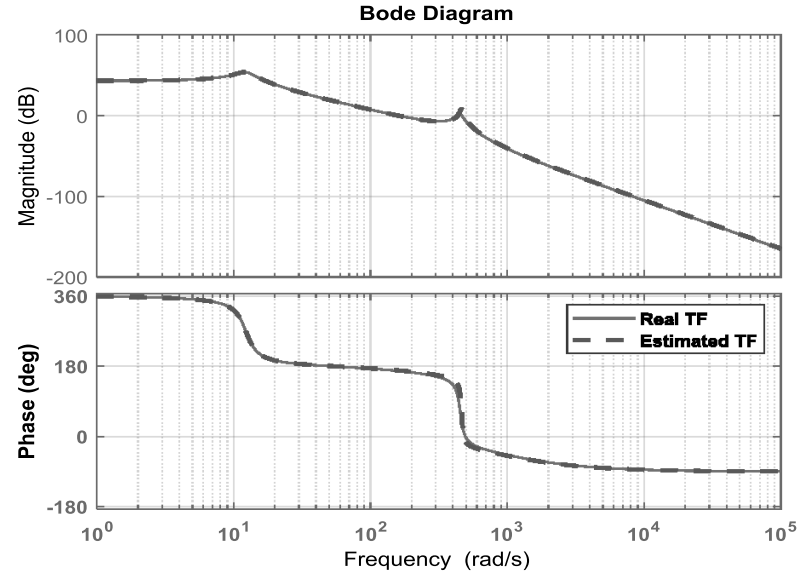

Fig. 6. Comparison of bode plot of the estimated frequency response and real control to the output transfer function in eq. (29). 
To validate the derived transfer function in eq. (29), the frequency response estimation technique is applied by injecting periodic signals to extract the information upon the process dynamics from the system. Matlab simulationbased frequency response of the system Simulink model is utilized. The frequency response of the system is computed by injecting sinestream into the input of the system model (duty cycle) and logging the output (rotation speed). The sinestream input signal is a set of frequency points from $10 \mathrm{rad} / \mathrm{s}$ up to $50 \mathrm{~K} \mathrm{rad} / \mathrm{s}$ with 134 linearly spaced frequency. Fig. 6 shows the bode plot of the computed frequency response along with the bode plot of the transfer function in eq. (29). This result reveals that both frequency responses are almost identical with $99.53 \%$ fit to the real transfer function data. Moreover, the computed transfer function from the frequency response estimator is

$$
\frac{\widehat{\omega}(s)}{\widehat{d}(s)}=\frac{-5.694 e 06 s+4.672 e 09}{s^{4}+23.75 s^{3}+2.152 e 05 s^{2}+7.865 e 05 s+3.252 e 07}
$$

Using open-loop speed control DC motors can be operated at any intermediate speed by changing the applied voltage or armature current. In this case, the speed cannot be precisely adjusted due to load variations on the motor shaft. Therefore, a closed-loop control is essential for DC motor applications, where constant speed is required, in which the motor measured speed is fed back to the speed controller. The block diagram of a closed-loop boost converter fed DC motor is shown in Fig. 7. A speed sensor is connected to the motor shaft; the measured speed of the sensor $w$ is fed back and compared with the reference speed $w^{*}$ to form the speed error $V_{e}$. The difference speed error is applied to the speed controller to generate a control voltage $V_{c}$, which adjusts the boost converter and produces the desired terminal voltage $V_{a}$. This terminal voltage controls the speed of the motor and thus the speed of the motor is maintained for any variations in the load torque. If the motor speed decreases from its desired value due to the application of additional load torque, the speed error $V_{e}$ at the output of the comparator increases. The speed controller responses with an increased control signal $V_{c}$ to increase the duty cycle of the boost converter and thus the converter output voltage (motor terminal) voltage $V_{a}$ is increase. This increased armature voltage develops more torque to compensate the effect of applied load torque and to restore the motor speed to its original value. On the contrary, if the speed of the motor is increased due to load reduction, the same operation in a reverse way is performed. When the produced electromagnetic torque matches the load torque then the motor speed will be constant at its reference speed.

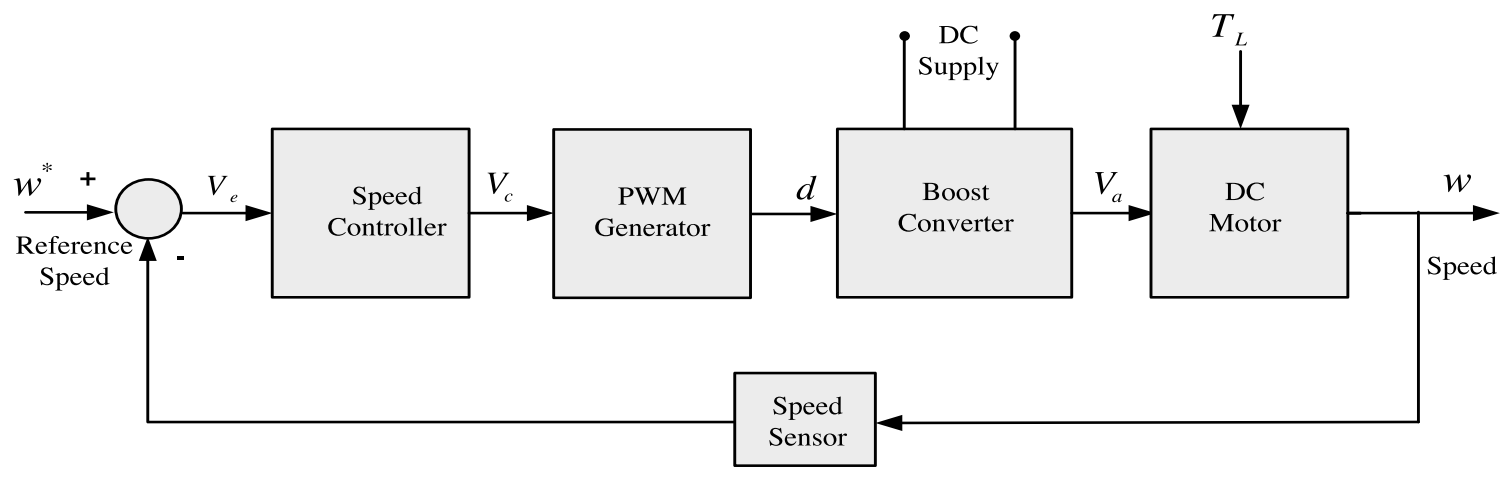

Fig. 7. Block diagram of the closed-loop boost converter fed PMDC motor. 


\section{PI CONTROLLER TUNING}

A simple PI controller has been used for close-loop speed implementation due to its smooth response and less steady state-error. PI controller parameters consist of two separate terms: proportional and integral values that denoted by $k_{p}$ and $k_{i}$. Appropriate setting of these parameters will improve the dynamic response, reduce overshoot. Eliminate steady state error and increase stability of the system (Mondal et al., 2020). The control signal $V_{c}(t)$ from the PI controller is given by

$$
V_{c}(t)=K_{p} e(t)+K_{i} \int e(t) d t
$$

where $w^{*}(t)$ is the reference speed, $w(t)$ is the actual speed and $e(t)=w^{*}(t)-w(t)$ is the speed error signal. The transfer function of the PI controller can be rewritten in Laplace domain as:

$$
C(s)=\frac{w^{*}(s)}{w(s)}=K_{p}+\frac{K_{i}}{s}
$$

Even though PI and PID tuning methods using heuristic approaches as genetic algorithms (GA) have been extensively studied by many researchers, the details on how the algorithms are implemented are still vague. This section intended to provide a better understanding on how PI controller is tuned. In this study, such parameters are optimized and tuned using Genetic algorithms (GA). To achieve a controller with optimal performance, several objective functions such as integral absolute error (IAE), integral square error (ISE), integral time absolute error (ITAE) and integral time square error (ITSE) (Ahmed et al., 2020; Zahir et al., 2018) under different operation conditions can be performed to estimate the best PI controller that produces best performance during dynamic and steady state responses. Each cost function will be used to obtain the optimum set of parameters and then the best set that gives the best response and performance will be considered.

GA is a random search approach that can be adapted to solve nonlinear problem of equations and optimize complex systems. GA employs probabilistic evolution sets instead of deterministic rules and treats a population of possible solutions known as entities or genes that progress iteratively. Each iteration of the algorithm is named a generation. The progress of solutions is simulated through an objective function and genetic operators such as reproduction, crossover, and mutation (Ahmed et al., 2020). This population (mating pool) is generally represented by a real-valued number or a binary string called a chromosome. The performance of the individual is measured and assessed by the objective function, which assigns each individual a corresponding number called fitness. The fitness of each chromosome is assessed, and a survival of the fittest strategy is applied. In this paper, the error between the reference speed and the actual speed is used to evaluate the fitness of each chromosome.

There are three main operations in a genetic algorithm: reproduction, crossover, and mutation. The computation is starting by initializing the parameters of the GA process using the values shown in Table 3 . Then generate a random population, $\mathrm{P}$, that consists of $n$ individuals of the controller parameters, $K_{p}^{1}$ and $K_{i}^{1}$, as shown in the following equations:

$$
\text { Population }=P=\left[\begin{array}{cc}
K_{p}^{1} & K_{i}^{1} \\
: & : \\
K_{p}^{n} & K_{i}^{n}
\end{array}\right]
$$

GA and its associated functions are implemented in Matlab script codes and simulation is done using Matlab/ Simulink. The sequences of operations involved in GA are described in the flowchart and the block diagram given in Fig. 8 and the details can be found in (Ahmed et al., 2020). 


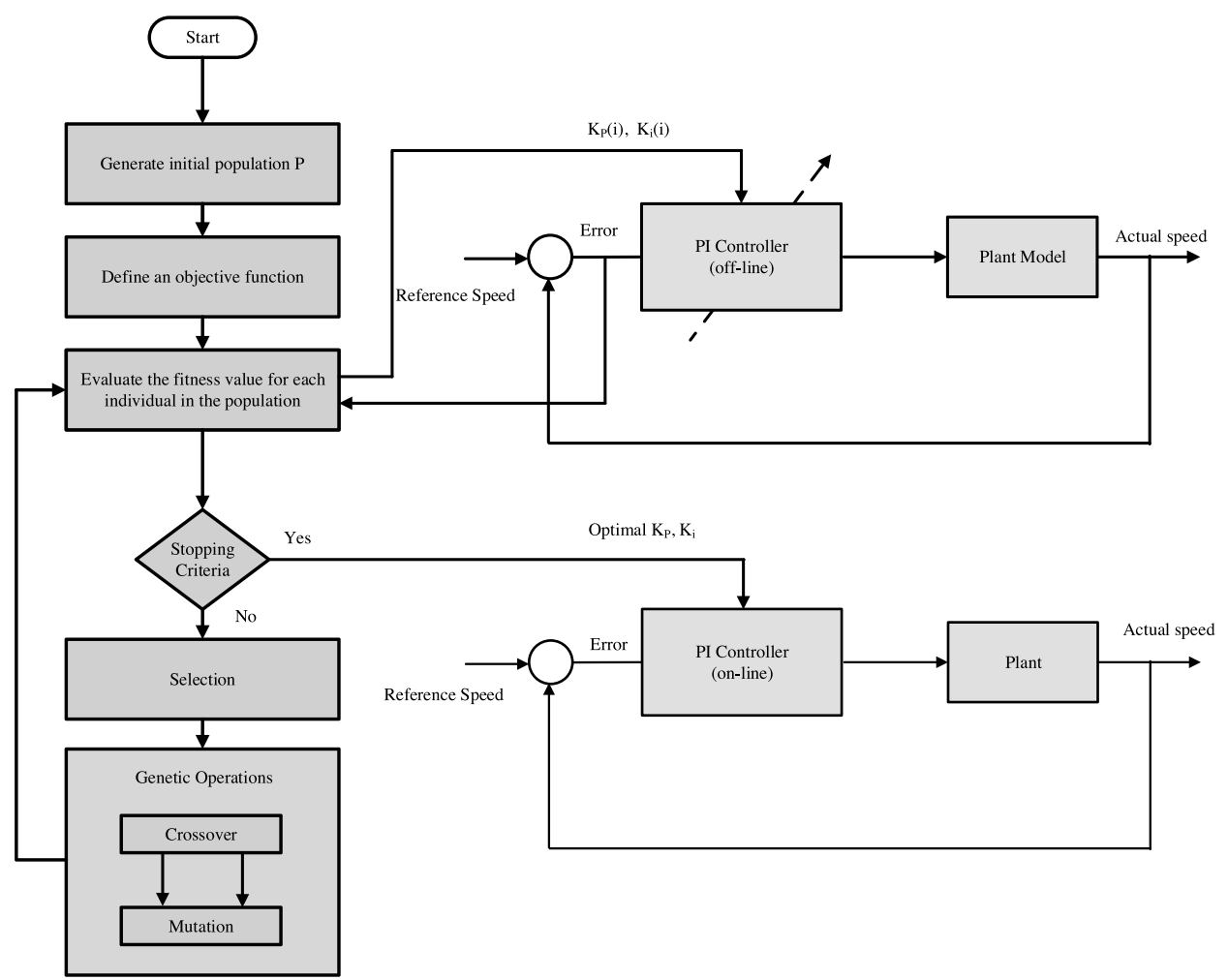

Fig. 8. Flow chart and block diagram of proposed GA tuning algorithm.

Table 2. GA parameters.

\begin{tabular}{|l|c|}
\hline \multicolumn{1}{|c|}{ Parameter } & Definition \\
\hline Population size & 45 \\
\hline Crossover rate & 0.8 \\
\hline Elitism rate & 0.05 \\
\hline Generation number & 20 \\
\hline Mutation rate & 0.01 \\
\hline
\end{tabular}

The parameters of the controller obtained by the end of the genetic algorithm tuning process using different objective functions are listed in Table 2. The tuned parameters using ITSE is selected for its excellent performance during dynamic and steady-state responses as smooth acceleration and no overshot.

Table 3. Tuned parameters obtained by GA.

\begin{tabular}{|c|c|c|c|c|}
\hline \multirow{4}{*}{ Controller } & \multicolumn{2}{|c|}{ Parameters } & \multicolumn{2}{c|}{ Cost Function } \\
\cline { 2 - 5 } & $K_{P}$ & $K_{I}$ & \multicolumn{2}{c|}{} \\
\cline { 2 - 5 } & 0.3492 & 1.1252 & ITAE & 0.971 \\
\cline { 2 - 5 } & 0.1719 & 0.0562 & ISE & 0.7948 \\
\cline { 2 - 5 } & 0.0052 & 0.0019 & ITSE & 0.814 \\
\hline
\end{tabular}


Using the PI controller tuned parameters, the overall closed-loop system transfer function is given as:

$$
\frac{\widehat{\omega}(s)}{\widehat{d}(s)}=\frac{-2.944 e^{-3} s^{2}+2.795 s+1.01}{4.75 e^{-6} s^{5}+1.9 e^{-4} s^{4}+8.53 e^{-3} s^{3}+0.196 s^{2}+0.5508 s+1.01}
$$

The closed-loop actual system is simulated in the Matlab/Simulink and a comparison between the unit step response of the proposed small-signal model and the Matlab simulated model is shown in Fig. 9. It is evident clearly, the great similarity between the response of the two models, which proves the validity of the proposed small signal-model. Fig. 10 shows the actual system response at different reference speed values with different PI tuned parameters obtained in Table 3.

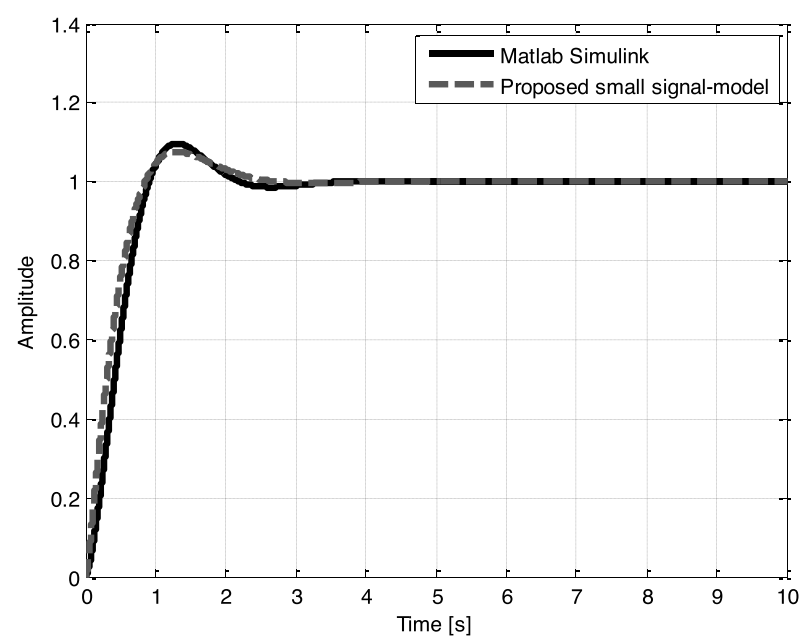

Fig. 9. Unit step response.

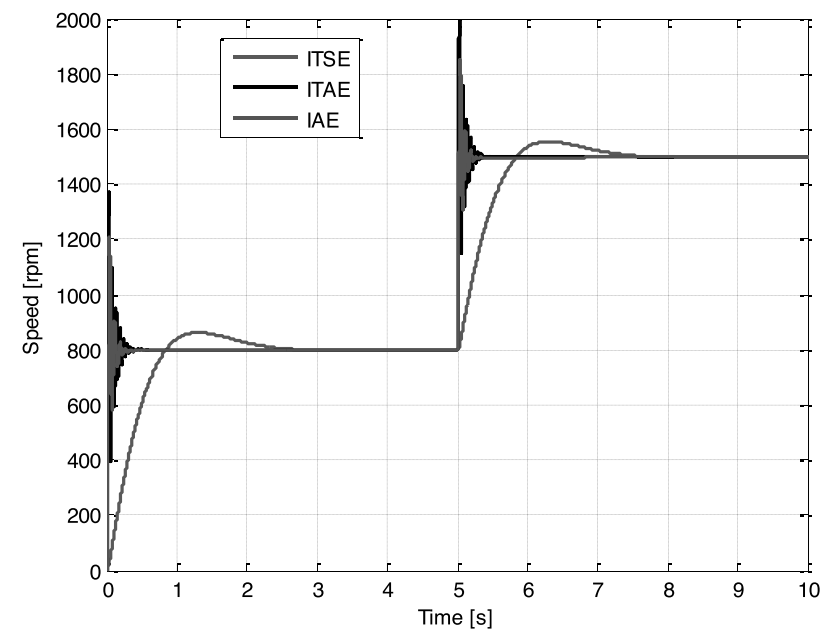

Fig. 10. Speed response at different reference speed.

\section{V. dSPACE DESCRIPTION}

The control signal, practically, for the switches in power converters prove to be a daunting task. Various digital circuit controlling methods have been considered to provide required trigging signals control power converters in literature. Among those methods are analogue circuit controllers (El-Hefnawi, 1997) microcomputers and fieldprogrammable gate arrays (FPGAs) (Melkhilev \& Rahim, 2002) digital signal processors (DSP) (Selvaraj \& Rahim, 
2009; Rodrigues \& Barton, 1979; Ghani et al., 2010, Ghani et al., 2011, Hanna et al., 2010). Controlling switches in power converters by dSPACE DSP has been adopted by researchers. Authors in (Salam, 2006) employed dSPACE controller in the design and control of a high-frequency link inverter. A grid-connected inverter is introduced in (Ghani, 2011; Hanna et al., 2010; Salam et al., 2006; Postiglione \& Simões, 2010) using dSPACE system as a rapid prototyping solution for laboratory implementation. An implementation of a three-phase renewable energy inverter by using the dSPACE DS1104 digital signal processing controller board is presented by (Ghani et al., 2010).

The dSPACE is a digital signal processing system that acts as a tie between control models built in Matlab/ Simulink and the hardware circuitry desired to be controlled (dSpace, 2018). To carry out the linkage task, software support is provided to facilitate Input/Output ports and peripherals thought Real Time Interface (RTI) library to read in and write out measured variables. Such I/O peripherals are A/D conversion, 16 parallel A/D converters supporting burst conversion mode, D/A conversion, 4 parallel D/A converters, Digital I/O Unit, 40 digital input channels and 40 digital output channels that can be used for (Bit I/O, PWM, signal generation (PWM), Square-wave signal generation, PWM signal measurement, Frequency measurement, and Incremental encoder interface. Fig. 11 depicts the block diagram of the dSPACE DS1103 controller board. It contains the core processor PowerPC603 with a clock speed of $250 \mathrm{MHz}$, a 64-bit floating-point processor, and a 16-bit DSP-Texas Instruments TMS320F240 microcontroller. This controller is typically extremely appealing for modeling and prototyping due to its cost-sensitive rapid control prototyping feature. It is particularly appropriate for the development of high-speed multivariable digital controllers and real-time simulations in various fields (Postiglione \& Simões, 2010).

When a given control scheme is designed and built in Simulink (including the required interface blocks for input and output ports), C-code is generated utilizing Real Time Workshop (RTW) functions. The C-code is compiled, linked, and loaded in memory to be executed, and thereby, performing the required controlling task. The dSPACE platform is accompanied by a software package called ControlDesk 5.1 Next Generation. This package supports some basic features of the automation to allow for comprehensive real time control and monitoring of control routine. The control desk environment provides several measuring instruments to measure results from the experimental setup. This enables to check and validate the system operation in real-time by displaying the variables, adjusting the system parameters and save results.

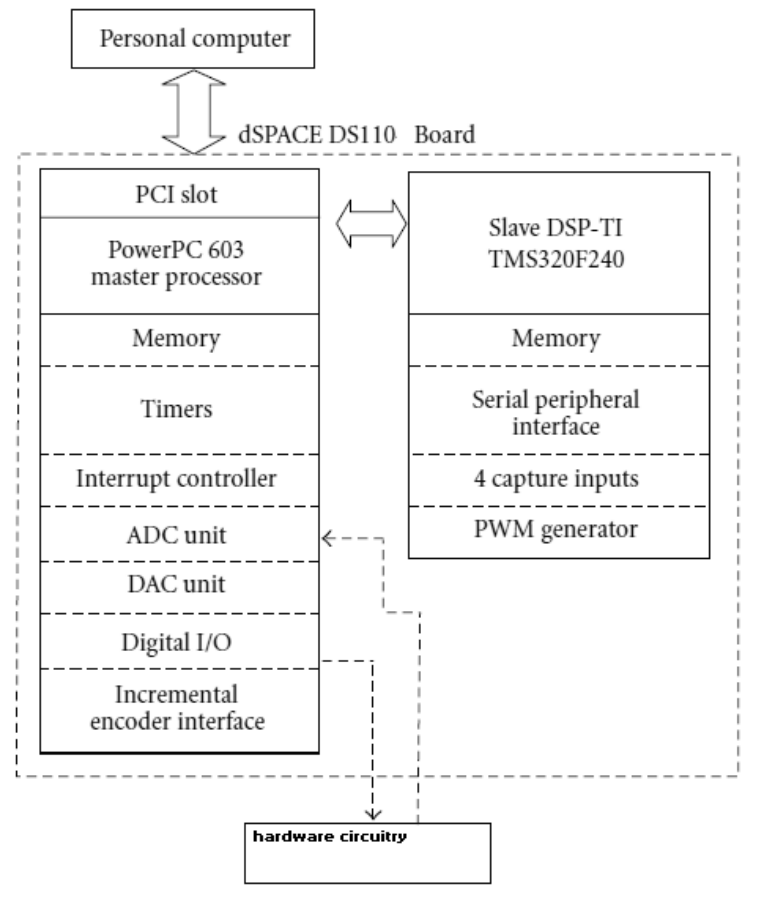

Fig. 11. Block diagram of the dSPACE control board. 


\section{EXPERIMENTAL VALIDATION AND DISCUSSIONS}

The proposed closed-loop boost converter fed DC motor is simulated and tested. To verify the principle of operation and the accuracy of the results, the system is built in the laboratory and checked for different study cases. The system configuration for the experimental setup is divided into two parts: a dSPACE DS1103-based digital signal processor and a power circuit. The dSPACE-based control board enables software flexibility and allows the implementation of the proposed control. The power circuit prototype rating of $1.0 \mathrm{~kW}(200 \mathrm{~V}, 5 \mathrm{~A})$ has been implemented using POWEREX CM150DY-12H IGBT as a boost switch, CS241210 fast recovery diode and PMDC motor rated 1.0kW, 200V, 5 A, $1500 \mathrm{rpm}$ coupled to a DC generator as an electric load. The parameters of hardware major components of the circuit used for experiments and simulation are presented in Table 1. The switching frequency used is $5 \mathrm{kHz}$. The DC supply voltage is set to be $30 \mathrm{~V}$ to give the motor rated voltage at a duty cycle of 0.8 .

Fig. 12 depicts the power circuit of the experimental setup. The voltage and current signals have been measured by LV 55-P and LA-55-P voltage and current transducers and the speed were measured by TECNEL (60V/1000rpm) tachogenerator. The tachogenerator voltage is not perfectly DC and has some voltage ripple. So, a filter is used to smooth the measured speed signal. VLA536-01R IGBT driver is used as an interface between the dSPACE and the IGBT boost switch. It must be noted that due to the limitation of the available measuring oscilloscope as it cannot accommodate the required bandwidth, all measured data are monitored in real-time and saved to the PC through Control Desk Next Generation ver. 5 accompanied with dSPACE platform for analysis interpretation and plotting.

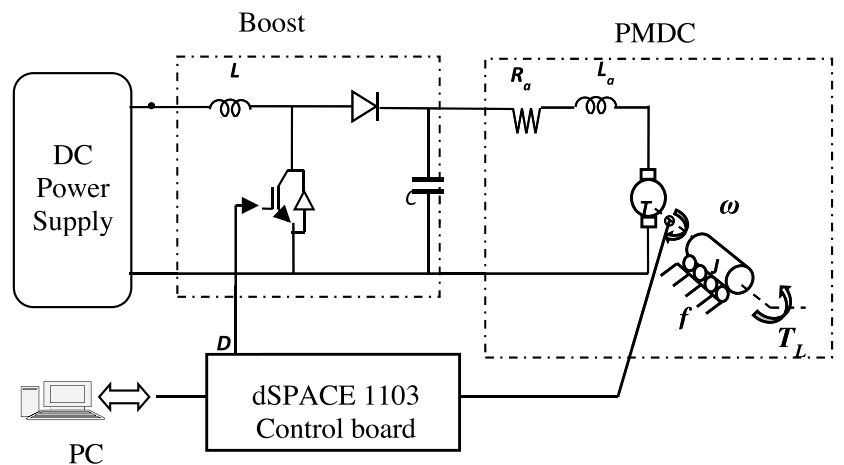

(a) Block diagram

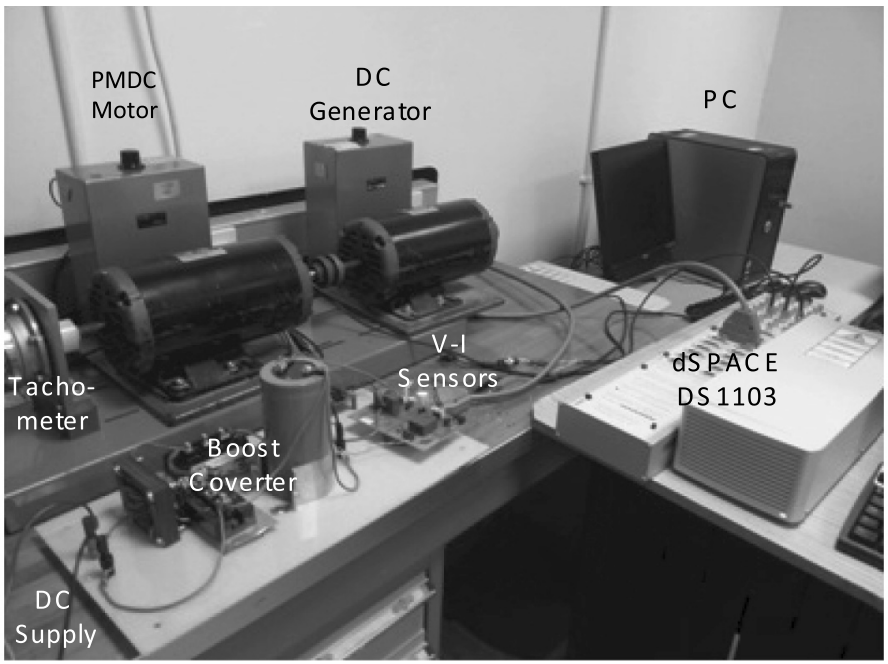

(b) Experiment setup.

Fig. 12. Total setup of the experimental system. 


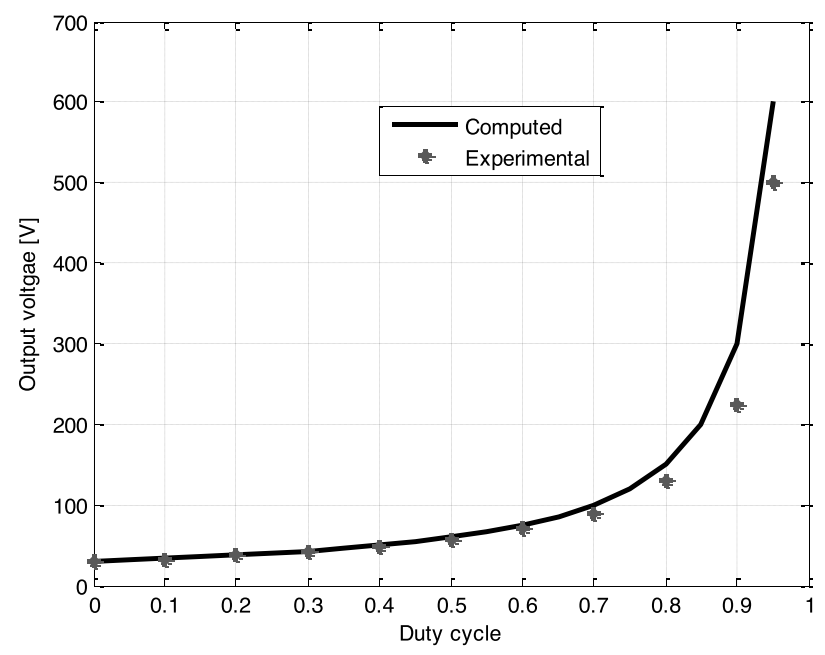

Fig. 13. Simulation and experimental variation of voltage gain $\left(V_{a} / V_{i}\right)$.

To test both the validity and viability of the proposed system, a series of experimental and simulation tests were performed. The results and discussion of the simulation and obtained experimental results are presented below. The computed and measured experimental voltage gain (armature voltage to input voltage characteristic) against the duty cycle is shown in Fig. 13. It is relevant to note that the armature voltage can be regulated from the input voltage to higher voltage values by controlling the boost converter duty cycle $\mathrm{D}$. The armature voltage is extremely sensitive to changes in duty cycle at higher values of duty cycles. From Fig. 13. it is clear to note that, the output voltage is controlled theoretically from 30 ; input voltage to $600 \mathrm{~V}$ by controlling the duty cycle $\mathrm{D}$ from 0 to 0.95 and is controlled experimentally from 0 to $220 \mathrm{~V}$; rated motor voltage; by controlling the duty cycle from 0 to 0.9 .

To evaluate the transient response and tracking performance of the system, a speed reference scenario is implemented (i.e. speed references of 1000, 1400, 1800, 1400, 1000 and $600 \mathrm{rpm}$; respectively), where each speed level lasts 30 seconds. The simulated and experimental tracking performance of the motor speed and the corresponding armature voltage, current and duty cycle are presented in Figs. 14 and 15. It is clear to depict that the speed responses reach the respective steady-state value without exhibiting the oscillation, which means that the system is capable of tracking the reference speed extremely well.
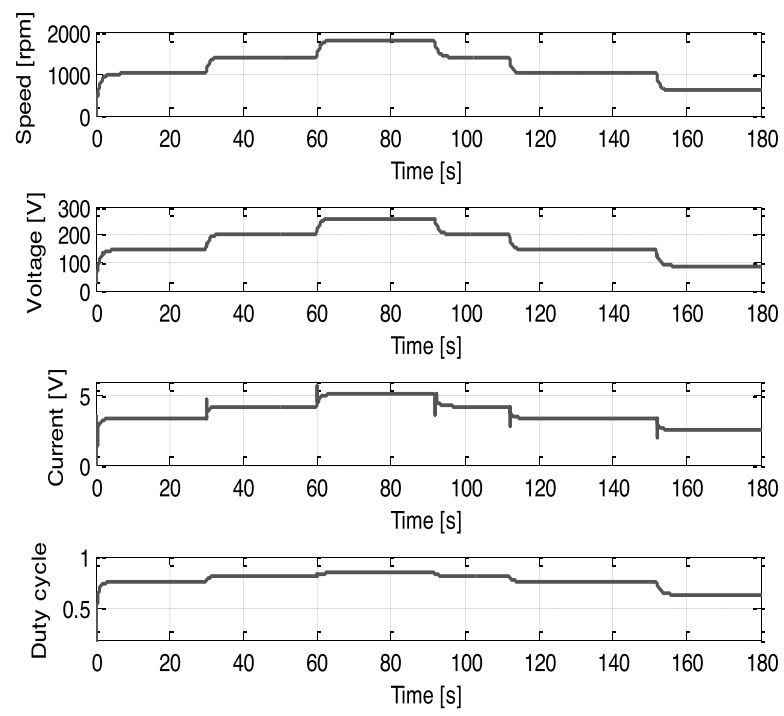

Fig. 14. Simulated tracking performance (motor speed, voltage, current and duty cycle). 


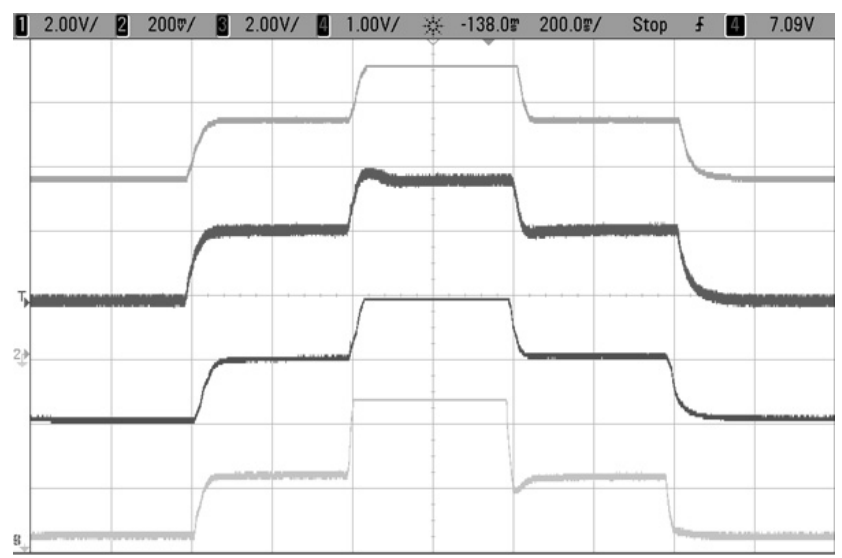

Fig. 15. Experimental tracking performance of the proposed system.

(motor speed, current, and duty cycle).

To validate the robustness of the proposed controller, the system is examined under load disturbance with different reference speed commands, and Fig. 16 illustrates the experimental variation of the motor speed, armature voltage, motor current and duty cycle variations for the same step change in the load torque. The load torque is suddenly applied to the motor shaft at a time of 40 second and continues till 95 second then it is removed abruptly. It is clear that the actual speed of the motor tracks extremely well the reference speed command. At time of 40 second the speed started to increase due to the load removal, the speed controller responses to decrease the control signal. This results in decreasing the duty cycle to adjust the motor applied voltage to the value required to maintain the motor speed to its reference value. At time of 95 second, the speed is decreased due to the load addition, consequently, the PI controller increased the duty cycle to apply higher armature voltage required to maintain constant speed operation.

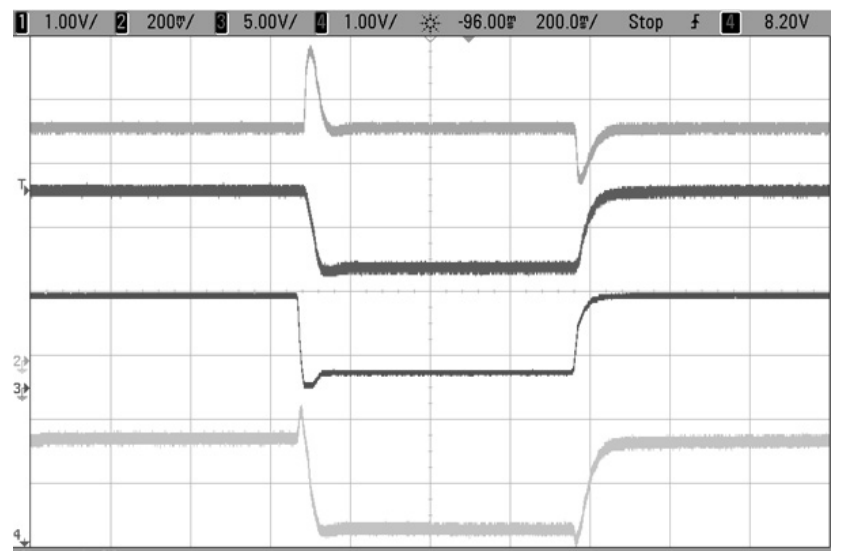

Fig. 16. System response under negative and positive load torque disturbance (motor speed, motor voltage, motor current and duty cycle).

\section{CONCLUSIONS}

The transfer function based on the small-signal model of boost converter fed permanent magnet DC motor has been presented in this paper. A general model of control-to-output transfer function was derived with the help of a computational symbolic algebra package in Mathcad software. The overall system performance has been assessed and verified experimentally based on a speed feedback control scheme for validation purposes. It was found that the proposed small signal-model of the boost converter fed PMDC motor is convenient for both transient and steady-state 
analyses. Also, the employment of computational symbolic algebra is advisable, as it has highly facilitated symbolic matrix manipulations and, thus, prevents the need for various simplifications or assumptions. The behavior of the proposed transient step response of the proposed small-signal model is verified through Matlab Simulink switching circuit simulator and hardware implementation. The obtained results are extremely useful for the exact simulation and analysis of boost converter circuits fed PMDC motors for vehicle applications to develop simplified models or practical design purposes. The results could be extended to boost converters for renewable energy applications as a solar water pumping system.

\section{REFERENCES}

A. Ayachit and M.K. Kazimierczuk. "Averaged Small-Signal Model of PWM DC-DC Converters in CCM Including Switching Power Loss,” IEEE Transactions on Circuits and Systems II: Express Briefs, vol. 66, pp. 262-266, 2019.

Ahmed A. AbdElhafez, Majed A. Aldalbehia, and Naif F. Aldalbehia. "Comparative Study for Machine Candidates for High Speed Traction Applications", International Journal of Electrical Engineering, vol. 10, no. 1, 2017.

Arindam Mondal, Prasanta Sarkar, Aliprio Hazra. "A unified approach for PI controller design in delta domain for indirect field-oriented control of induction motor drive," Journal of Engineering Research, vol. 8, no. 3, 2020, pp. 118-134.

B. Ragavendra, S. Vijayanand, and B. Jayaprakash. "Improved Control Strategy on Cuk fed DC Motor using Artificial Bee Colony Algorithm," in International Conference on Trends in Mechanical, Aeronautical, Computer, Civil, electrical and Electronics Engineering (ICMACE14). vol. 2, 3, 2014, pp. 181-188.

B.C. Barry et al., "Small-Signal Model of the Two-Phase Interleaved Coupled-Inductor Boost Converter," in IEEE Transactions on Power Electronics, vol. 33, no. 9, Sept. 2018, pp. 8052-8064,

B.C. Barry, J.G. Hayes, M.S. Rylko, R. Stala, A. Penczek, A. Mondzik, and R.T. Ryan. "Small-signal model and control of the interleaved two-phase coupled-inductor boost converter," 2016 IEEE Energy Conversion Congress and Exposition (ECCE), Milwaukee, WI, 2016, pp. 1-6.

Bhatt Pooja, Mehar Hemant, and Sahajwani Manish. "Electrical Motors for Electric Vehicle - A Comparative Study", Proceedings of Recent Advances in Interdisciplinary Trends in Engineering \& Applications (RAITEA), April 3, 2019.

dSPACE-DS1103, 2018. Hardware Installation and Configuration and ControlDesk Experiment Guide, Paderborn, Germany.

E. Guerrero, J. Linares, E. Guzmán, H. Sira, G. Guerrero and A. Martínez. "DC Motor Speed Control through Parallel DC/ DC Buck Converters”, IEEE Latin America Transactions, vol. 15, no. 5, pp. 819-826, May 2017.

F. Grasso, S. Manetti, M.C. Piccirilli, and A. Reatti. "A Laplace transform approach to the simulation of DC-DC converters," International Journal of Numerical Modelling: Electronic Networks, Devices and Fields, vol. 32, p. e2618, 2019.

Gagandeep Luthra. "Comparison of Characteristics of Various Motor Drives Currently Used in Electric Vehicle Propulsion System", International Journal of Mechanical And Production Engineering, vol. 5, no. 6, June 2017, pp. 38-41.

Ghani Z.A., Hannan M. and Mohamed A., 2010. Renewable Energy Inverter Development using dSPACE DS1104 Controller Board, in 2010 IEEE International Conference on Power and Energy (PECon2010) Kuala Lumpur, Malaysia, 2010, 69-73.

Ghani Z.A., Hannan M.A. and Subiyanto A.M., 2011. Three-Phase Photovoltaic Grid-Connected Inverter using dSPACE DS1104 Platform," IEEE PEDS 2011 Singapore, pp. 474-451.

G.N. Love. "Small signal modelling of power electronic converters, for the study of time-domain waveforms, harmonic domain spectra, and control interactions," P.h.D thesis, Electrical and Computer Engineering, University of Canterbury, Jan. 2007.

Hannan M.A., Ghani Z.A., and Mohamed A., 2010. An Enhanced Inverter Controller for PV Applications Using the dSPACE Platform," International Journal of Photoenergy, vol. 2010, 1-10, 2010.

H. Zhang, M. Jing, W. Liu, and D. Dong. "Multiple-Harmonic Modeling and Analysis of Single-Inductor Dual-Output Buck DC-DC Converters," IEEE Journal of Emerging and Selected Topics in Power Electronics, vol. 8, pp. 3260-3271, 2020.

H.B. Shin, E.S. Jang, J.G. Park, H.W. Lee and T.A. Lipo. "Small-signal analysis of multiphase interleaved boost converter with coupled inductors," in IEE Proceedings - Electric Power Applications, vol. 152, no. 5, Sept. 2005, pp. 1161-1170.

I. Lachkar, F. Giri, M. Haloua, and A. Abouloifa. "DC motor speed control through AC/DC converter," in Computer Aided 
Control System Design, IEEE International Conference on Control Applications, IEEE International Symposium on Intelligent Control, 2006m pp. 2450-2455.

Jinke Zhang and Lei Guo. "Theory and design of pid controller for nonlinear uncertain systems", IEEE Control Systems Letters, vol. 3, no. 3, pp. 643-648, 2019.

K. Alothman, Nabil A. Ahmed, M.E. AlSharidah, K.M. Elnaggar and B.N. Alajmi. "Experimental Implementation of PEM Fuel Cell Powered DC Motor for Vehicle Applications", Journal of Engineering Research, vol. 4, no. 3, Sep. 2016, pp. 95113.

K. Khatun, V.V. Ratnam, A.K. Rathore, and B.L. Narasimharaju. "Small-Signal Analysis and Control of Soft-Switching Naturally Clamped Snubberless Current-Fed Half-Bridge DC/DC Converter,” Applied Sciences, vol. 10, p. 6130, 2020.

MATHCAD, MathSoft Inc., 101 Main Street, Cambridge, Massachusetts, 02142 USA, http://www.mathsoft.com

MATLAB Simulink (TM), The Math works Inc, 2019b Apple Hill Drive, Natick MA 01760-2098 USA, http://www.mathworks. com.

Melkhilev S. and Rahim N.A., 2002. XilinX FPGA Based Three-Phase PWM Inverter and Its Application for Utility Connected PV System,” in Proceeeding of IEEE TENCON, 2002, 2079-2082.

M. Abbasi, A. Afifi, and M.R.A. Pahlavani. "Comments on "A Single-Inductor Multiple-Output Switcher With Simultaneous Buck, Boost, and Inverted Outputs”," IEEE Transactions on Power Electronics, vol. 34, pp. 1980-1984, 2019.

M. Forouzesh, Y.P. Siwakoti, F. Blaabjerg, and S. Hasanpour. "Small-Signal Modeling and Comprehensive Analysis of Magnetically Coupled Impedance-Source Converters," IEEE Transactions on Power Electronics, vol. 31, pp. 7621-7641, 2016.

M. Arjun, V.V. Ramana, R. Viswadev and B. Venkatesaperumal, "Small Signal Model for PV Fed Boost Converter in Continuous and Discontinuous Conduction Modes," in IEEE Transactions on Circuits and Systems II: Express Briefs, vol. 66, no. 7, July 2019, pp. 1192-1196.

Mohammed H. Rashid, 2014. Power Electronics: Circuits, Devices and Applications, $4^{\text {th }}$ Ed., Pearson, 2014.

Nabil A. Ahmed. "Modeling and Simulation of AC-DC Buck-Boost Converter Fed DC Motor with Uniform PWM Technique," Electric Power Systems Research, vol. 73, 2005, pp. 363-372.

N. Kondrath, and M.K. Kazimierczuk. "Control-to-output transfer function of peak current mode controlled pulse-width modulated DC-DC buck converter in continuous conduction mode", IET Power Electronics, vol. 5, no. 5, May 2012, pp. $582-590$.

N.A. Ahmed, S. Abdul Rahman, and B.N. Alajmi. "Optimal controller tuning for P\&O maximum power point tracking of PV systems using genetic and cuckoo search algorithms," International Transactions on Electrical Energy Systems, vol. n/a, p. e12624.

P. Hridya, Anu Anto, Aiswary Raj, and U.P Syama. "Comparison of Speed Control of DC Motors with Buck Buckboost and CUK Converter", Control Power Communication and Computing Technologies (ICCPCCT) 2018 International Conference on, pp. 386-391, 2018.

Postiglione C.d.S. and Simões M.G., 2010. dSPACE Based Implementation of a Grid Connected Smart Inverter System,” 2010 IEEE 12th workshop Control and Modeling for power Electronices Boulder, CO: IEEE, 1-5.

Rodrigues F. and Barton T.H., 1979. A McMurray Inverter Controller, IEEE Transactions On Industrial Electronics and Control Instrumentation (IECI), vol. 26, 156-160.

Salam Z., Soon T.L., and Ramli M.Z., 2006.“Hardware implementation of the high frequency link inveter using the dSPACE DS1104 digital signal processing board, in Proceedings of the 1st International Power and Energy Conference (PECon '06), 348-352.

S. Kapat, G.R. Chilukuri, and S. Jash. "Small-Signal Modeling of SIMO DC-DC Converters and Comparative Continuous/ Discrete-Time Results," in 2020 IEEE 21st Workshop on Control and Modeling for Power Electronics (COMPEL), 2020, pp. 1-5.

S.H. El-Hefnawi. "Digital Firing and Digital Control of A Photovoltaic Inverter," Renewable Energy, vol. 12, 1997, pp. 315-320. 
S.R. Jape, and A. Thosar. "Comparison of Electric Motors for Electric Vehicle Application", vol. 6, no. 9, International Journal of Research in Engineering and Technology, Sep. 2017, pp. 12-17.

S.S. Dash, B. Nayak, and S. Kumar. "Feedback Control and Dynamic Behaviour of Z-Source Converter Fed Separately Excited DC Motor and Centrifugal Pump Set," vol. 6, 2014, pp. 1601-1614.

Selvaraj J. and Rahim N.A. 2019. "Multilevel Inverter for Grid-Connected PV System Employing Digital PI Controller," IEEE Transaction On Industrial Electronics, vol. 56, 149-158.

Stephen, S. Ben John, and T. Ruban Devaprakash. "Improved control strategy on buck-boost converter fed DC motor with fuzzy logic controller." Advances in Natural and Applied Sciences, vol. 8, no. 20, 2014, p. 79-83.

Tanjim Tarannum. "Intelligent Speed Control of DC Motor using ANFIS D Controller", Advances in Science Engineering and Robotics Technology (ICASERT) 2019 1st International Conference on, pp. 1-5, 2019.

T. Porselvi, M.K. Srihariharan, J. Ashokj, and Ajith Kumar. "Selection of Power Rating of an Electric Motor for Electric Vehicles", vol. 7, no. 4, International Journal of Engineering Science and Computing IJESC, 2017, pp. 6469 -6472.

Thanh Anh Huynh, and Min-Fu Hsieh. "Performance Analysis of Permanent Magnet Motors for Electric Vehicles (EV) Traction Considering Driving Cycles", MDPI Energies, vol. 11, no. 6, May 2018, 1385.

V, Viswanatha. "A Complete Mathematical Modeling, Simulation and Computational Implementation of Boost Converter via Matlab/simulink," INA-Rxiv, 9 June 2019. Web.

Xiangdong Liu, Hao Chen, Jing Zhao and Anouar Belahcen. "Research on the Performances and Parameters of Interior PMSM Used for Electric Vehicles", IEEE Transactions on Industrial Electronics, vol. 63, no. 6, June 2016, pp. 3533-3545.

Ying Qiu, Xiyou Chen, Chongquan Zhong, and Chen Qi. "Uniform Models of PWM DC-DC Converters for Discontinuous Conduction Mode Considering Parasitics", Industrial Electronics IEEE Transactions on, vol. 61, no. 11, pp. 6071-6080, 2014.

Zahir, A.A.M., Alhady S.S.N., Othman W.A.F.W., and Ahmad M.F., "Genetic Algorithm Optimization of PID Controller for Brushed DC Motor,” In Intelligent Manufacturing \& Mechatronics, 427-437, 2018, Springer, Singapore.

Z. Dong, C.K. Tse, and S.Y.R. Hui, “Current-Source-Mode Single-Inductor Multiple-Output LED Driver With Single Closed-Loop Control Achieving Independent Dimming Function," IEEE Journal of Emerging and Selected Topics in Power Electronics, vol. 6, pp. 1198-1209, 2018. 